\title{
Peptide-based targeting strategies for simultaneous imaging and therapy with nanovectors
}

\author{
Antonella Accardo, Diego Tesauro and Giancarlo Morelli \\ Over recent years, multifunctional compounds that combine diagnostic and therapeutic modalities using one unified material \\ have been developed and designated as theranostics. These compounds provide the chance to develop individually designed \\ therapies against various diseases to accomplish personalized medicine. In this review, theranostic agents based on nanovectors \\ (liposomes, naposomes, micelles, polymeric micelles and micelles built around a solid core) externally modified with targeting \\ peptides able to simultaneously carry a drug and a contrast agent are described, demonstrating that peptide-modified \\ nanovectors can selectively carry a drug to target cells with an imaging probe co-incorporated into the nanovector \\ to monitor therapy.
}

Polymer Journal (2013) 45, 481-493; doi:10.1038/pj.2012.215; published online 13 February 2013

Keywords: doxorubicin; liposomes; nanosystems; peptides; polymeric micelles; theranostics

\section{INTRODUCTION}

Cancer remains one of the leading causes of mortality worldwide, affecting more than 10 million new patients every year. Currently, treatment options include surgical resection, radiation, and chemotherapy. Although more than 90 chemotherapeutic drugs have been approved by the Food and Drug Administration (FDA) for clinical use, their efficacy has been severely hindered due to doselimiting toxicity and patient morbidity. In many cases, a large amount of the administered drug is also delivered to normal tissue, which could cause the severe side effects that patients often experience. ${ }^{1}$ Therefore, an essential approach for overcoming this crucial obstacle is the development of optimized and targeted delivery systems. ${ }^{2}$ The overexpression of specific receptors has been documented for a variety of cancers. As many as $10^{5}-10^{6}$ receptor molecules per cell or receptor densities in the $\mathrm{pmol} \mathrm{mg}^{-1}$ protein range have been reported for a variety of systems, such as transferrin receptors in hematologic and other malignancies, somatostatin receptors in neuroendocrine tumors, CCK2 receptors in medullary thyroid cancer, bombesin receptors in prostate and breast carcinoma and several others. ${ }^{3-5}$ Consequently, the conjugation of drugs or contrast agents with receptor-binding molecules can selectively increase their adherence to or uptake by target cells. ${ }^{6-9}$ For this purpose, various targeting molecules, such as antibodies (Ab), antibody fragments, peptides, nucleic acid (DNA/RNA aptamer) small molecules, or others (vitamins or carbohydrates), have been used for target-selective therapeutic and/or diagnostic applications. Antibodies with two epitope-binding sites in a single molecule offer remarkably high binding affinities and selectivities for the target of interest. Several examples of antibodies approved by the FDA for therapeutic use are rituximab (Rituxan) for non-Hodgkin's lymphoma treatment, ${ }^{10}$ trastuzumab (Herceptin) for breast cancer treatment, ${ }^{11}$ bevacizumab (Avastin) to inhibit angiogenesis, ${ }^{12}$ and cetuximab (Erbitux) for colorectal cancer treatment. ${ }^{13}$ Currently, seven human monoclonal antibodies mAbs have been approved in the United States and in the European Union, and many others are in clinical development. Adalimumab, specific to tumor necrosis factor (TNF), was the first human mAb approved by the FDA in 2002. ${ }^{14}$ Aptamers are small nucleic acid ligands (15-40 bases) that can bind specifically to targets due to their ability to fold into unique conformations with threedimensional structures. ${ }^{15}$ Pegaptanib, a VEGF165-targeted aptamer, was approved by the FDA in 2004 for the treatment of neovascular macular degeneration, while AS1411, a nucleolin-targeted aptamer, is in phase II of clinical development. ${ }^{16-18}$ Although aptamers and monoclonal antibodies (mAbs) have been widely used as escort molecules for the targeted delivery of nanoparticles, they possess several unfavorable properties. Aptamers have rapid blood clearance, largely due to nuclease degradation. To overcome this difficulty, pyrimidine modifications at the $2^{\prime}$-fluorine position or chemical modifications with PEG have been used to enhance the bioavailability and the pharmacokinetic properties. ${ }^{19}$ On the other hand, mAbs are expensive to manufacture and present some degree of variation from batch to batch. Moreover, the development of targeted $\mathrm{mAb}$ nanoparticles is limited by the large antibody size and by the difficulty in conjugating mAbs to nanoparticles. Thus, other smaller-sized ligands, including peptides, have recently attracted more attention. Currently, several peptides, such as cilengitide (a cyclic peptide able to selectively recognize integrin receptors) and adnectin (Angiocept for human VEGF receptor 2), are in clinical trials 
for the treatment of non-small cell lung cancer and pancreatic cancer ${ }^{20}$ and for the treatment of advanced solid tumors and nonHodgkin's lymphoma.

Peptides present some drawbacks and advantages compared with antibodies in their use as targeting molecules. The drawbacks are related to a low target affinity and metabolic instability due to enzymatic degradation. Strategies to improve the metabolic stability and pharmacokinetics could be based on the modification of the peptide sequence, such as the introduction of D-amino acids or multivalent sequences. Peptide advantages consist of their low immunogenicity, low cost, stability, long-term storage and easy handling. ${ }^{21}$ Furthermore, the associated risks from unintended effects on the host immune system is low, and their small size is less likely to change the optimized physicochemical properties of nanoparticles. ${ }^{22}$ Peptide-based targeting ligands can be identified via several methods. Most commonly, they are obtained from the binding regions of the protein of interest or from modeling new sequences on the structure of the target receptor. Phage display techniques can also be used to identify peptide-targeting ligands.

In recent years, the idea of combining several functions in the same compound has gained popularity. For example, researchers realized that the complementary abilities of different imaging modalities could be utilized to great effect by using the modalities together. ${ }^{23,24}$ In fact, no single imaging modality currently provides the combination of sufficiently high sensitivity with a high spatial and temporal resolution. Many hybrid systems that combine two or more of these imaging modalities, such as PET (positron-emission tomography) and SPECT (single-photon-emission computed tomography) in combination with $\mathrm{CT}$ (computed tomography) and/or MRI, are commercially available and others are under active development. ${ }^{25}$ Moreover, for the nuclear imaging techniques PET and SPECT, radioactive tracers are used; they provide information in a sensitive, non-invasive, and quantitative manner. Just as multiple species of imaging probes can be combined in a single compound, molecules with therapeutic functions can be incorporated, thus yielding probes with combined therapeutic and diagnostic functions. The goal is to use imaging probes as tools to guide or to monitor therapy. The term 'theranostic' was recently coined to describe multifunctional compounds that are able to combine diagnostic and therapeutic modalities in one unified material, providing the chance to develop individually designed therapies against various diseases to accomplish personalized medicine. ${ }^{26}$

A theranostic nanomedicine approach could improve personal medicine by means of several essential issues: (i) the optimization of drug delivery systems via a noninvasive assessment of the pharmacokinetics, biodistribution and target site localization of conjugated or entrapped pharmacologically active agents; (ii) the prediction of treatment responses by combining information on the overall target site localization with noninvasive imaging insights into the local distribution of the drug and/or of the carrier material at the target site; (iii) defining the efficacy of drug delivery systems by using contrast agents to monitor the release of pharmacologically active agents from stimuli-sensitive nanomedicines. In other words, theranostic systems providing real-time feedback on the efficacy of targeted therapeutic interventions could be used to facilitate preclinical efficacy analysis, to prescreen patients, and to generate optimal clinical treatments for each patient. ${ }^{27}$ It can be reasoned that treatment should be continued only for patients who show high levels of target site uptake and that for those patients in whom this is not the case, other therapeutic options should be considered. In the present review, we focused our attention on target-selective theranostic agents based on nanovectors that are able to carry, simultaneously, a drug and a contrast agent and that are externally modified with targeting peptides (see Table 1).

\section{NANOSYSTEM-BASED THERANOSTICS}

Recently, nanoscopic $(10-500 \mathrm{~nm})$ systems, such as polymeric micelles, polymer-drug conjugates, dendrimers, liposomes, and inorganic particulates, that incorporate therapeutic agents, molecular targeting, and diagnostic imaging capabilities are emerging as the next generation of multifunctional nanomedicines for improving the therapeutic outcome of drug therapy. ${ }^{28-31}$

Several authors have highlighted the importance of using targeted nanoparticles, which are functionalized with antibodies, peptides,

Table 1 Peptide, receptor system, therapeutic and diagnostic agent for each described theranostic nanostructure are reported

\begin{tabular}{|c|c|c|c|c|c|}
\hline Nanosystem & Peptide & Receptor & Therapeutic agent & Diagnostic agent & Ref. \\
\hline \multirow[t]{4}{*}{ Liposomes } & cRGDfK & integrin $\alpha \mathrm{v} \beta 3$ & Dox & BODIPY & 45 \\
\hline & CSNIDARAC & integrin $\alpha v \beta 6$ & Dox & Сy7.5 & 47 \\
\hline & CCK8 & Cholecystokinin & Dox & ${ }^{111}$ In-DTPAGlu & 58 \\
\hline & {$[7-14] B N$} & GRP & Dox & ${ }^{111}$ In-DTPA & 60 \\
\hline \multirow[t]{3}{*}{ Polymeric Micelles (PM) } & GRGDS-NH2 & integrin $\alpha v \beta 3$ & MTX & Gd MOF & 64 \\
\hline & cRGD & integrin $\alpha \mathrm{v} \beta 3$ & Dox & ${ }^{64}$ Cu-NOTA & 65 \\
\hline & CRKRLDRNC & $\mathrm{IL}-4$ & Dox & Cy5.5 & 68 \\
\hline \multirow[t]{8}{*}{ Iron oxide nanoparticles } & F3 & nucleolin & Photofrin & Iron oxide & 70 \\
\hline & cRGD & integrin $\alpha v \beta 3$ & Dox & SPIO & 72 \\
\hline & RGDLATLRQL & integrin $\alpha v \beta 6$ & Dox & SPIO & 73 \\
\hline & RGD & integrin $\alpha v \beta 3$ & PAV & Iron oxide/Cy7 & 74 \\
\hline & CREKA/CRKDKC & - & - & SPIO/Cy7 & 76 \\
\hline & CGKRK & GBM & $\mathrm{D}[\mathrm{KLAKLAK}]_{2}$ & Iron oxide & 77 \\
\hline & СTX & /Brain & siRNA & Iron oxide & 79 \\
\hline & EPPT & uMUC-1 & SiRNA & SPION/Cy5.5 & 81 \\
\hline Gold Nanoparticles & tTF-RGD & integrin $\alpha \mathrm{v} \beta 3$ & Dox/Gold-NRs & SPIO & 82 \\
\hline Quantum dots & cRGD & integrin $\alpha v \beta 3$ & Dox & QD & 86 \\
\hline Mesoporus silica & cRGDyK & integrin $\alpha \mathrm{v} \beta 3$ & PdTPP & ATT0647N & 87 \\
\hline particles & SP94 & - & Dox & Calcein/Alexa QDs/fluor 647 dsDNA/RFP & 88 \\
\hline
\end{tabular}


aptamers and small organic molecules, for cancer therapy and diagnosis. . $^{27,32,33}$

In cancer therapy, nanosystems exhibit several potential advantages with respect to conventional small molecule-based therapy. ${ }^{34}$ They present a high payload capacity, reduced toxicity to healthy tissue, and improved antitumor efficacy. When intravenously injected, particles smaller than $5 \mathrm{~nm}$ are removed from the blood by rapid renal clearance through the kidneys, while large microsized particles are filtered mechanically by the sinusoids and cleared by the reticuloendothelial system (RES) of the liver and spleen. ${ }^{35}$ Moreover, due to the incomplete tumor vasculature (vessels with enlarged gap junctions of $100 \mathrm{~nm}$ to $2 \mu \mathrm{m}$ ), nanosystems can selectively extravasate into tumor tissue more rapidly than drugs with lower molecular weights and can remain there for an extended period of time (days to weeks). ${ }^{36,37}$ This phenomenon, identified as 'enhanced permeability and retention (EPR) effect', was developed by Maeda and colleagues ${ }^{38}$ and represents a form of selective delivery termed 'passive targeting. Therefore, nanoparticles $10-500 \mathrm{~nm}$ in size can remain in circulation for an extended period of time when injected intravenously and can be employed in strategies for targeted delivery, such as passive or active targeting. ${ }^{39}$ Moreover, 'active targeting' is realized by using nanoparticles externally modified with targeting molecules, such as antibodies or peptides.

\section{LIPOSOMES}

The most popular and clinically established nanometer-scale drug carriers are liposomes and micelles. Liposomes are used to deliver cytotoxic and antifungal drugs, genes, and vaccines, as well as imaging agents. ${ }^{40}$ They are unilamellar or multilamellar phospholipid vesicles with an aqueous phase inside and with a size ranging from 50$500 \mathrm{~nm}$. Liposomes offer several advantage compared with traditional delivery systems. Liposomes are easily prepared from commercial or synthetic phospholipids; moreover, their external surfaces can be modified by simply adding a chemical functional group. The ability to easily manipulate their sizes and surfaces leads to the outstanding advantages that liposomes offer over other delivery systems. Liposomes are excellent carriers for drug delivery; hydrophilic drugs can be encapsulated in the inner aqueous compartment while poorsoluble drugs can be solubilized in the phospholipid bilayer. The encapsulation of cytotoxic and/or cardiotoxic drugs in liposomes modifies their tissue distribution and their pharmacokinetics. For example, the conventional drug doxorubicin (Dox) is an established cytotoxic agent for many cancer types, in particular for breast and ovarian cancer, and its use has been shown to be clinically effective. However, irreversible cardiac toxicity has been a primary doselimiting factor in the use of this drug. A successful strategy for reducing the cardiac toxicity associated with Dox involves its encapsulation in liposomes, which alters the tissue distribution and the pharmacokinetics of this drug while maintaining the efficacy and improving the therapeutic index. ${ }^{41,42}$ Liposomal doxorubicin formulations (for example Myocet and Caelyx/Doxil) have shown reduced cardiac toxicity compared with free Dox while preserving the antitumor efficacy. ${ }^{434}$ An example of liposomal doxorubicin decorated with a cyclic RGDfK peptide for imaging and for treating a metastatic disease was reported by Cheresh et al. ${ }^{45}$ This peptide sequence selectively recognizes the $\alpha v \beta 3$ integrin receptor that is expressed on angiogenic endothelium. ${ }^{46}$ RGD liposomes (DSPC/Chol/DOPE/DSPE-mPEG2000/DSPE-cyclic RGDfK) were formulated using standard preparation procedures, and Dox was encapsulated via remote loading at $55^{\circ} \mathrm{C}$ to produce RGD-Dox-NPs. Moreover, the liposomes were made fluorescent by the insertion of
$1 \%$ of the fluorophore DOPE-BODIPY 630/650. The in vivo binding ability and tumor efficacy of the RGD-Dox-NPs (targeted NPs) with respect to RAD-Dox-NPs (RAD is a control peptide with the cRADfK sequence) were determined using mice bearing the basic fibroblast growth factor (bFGF). An apoptotic effect was observed only for the targeted NPs, and, in particular, the authors observed a reduction in the primary tumor growth $(23 \%)$ and a significant reduction in metastasis $(82 \%)$ in an orthotopic pancreatic tumor model that included metastatic lesions in the hepatic hilar lymph node 7 days after injection.

Theranostic liposomal Dox was also studied by Lee and colleagues $^{47}$ for the imaging of doxorubicin at and the targeted delivery of doxorubicin to a lung tumor. Lung cancer is the leading cause of death due to cancer, and its high mortality rate appears to be derived from a low therapeutic index for chemotherapy and from late detection due to a lack of sensitive diagnostic biomarkers. The identification of novel biomarkers for early lung cancer detection remains a challenge. In this study, a novel peptide (CSNIDARAC) with a high binding affinity for lung tumors was identified by the in vitro screening of a phage display peptide library, and CSNIDARAC peptide-conjugated liposomal Dox (Lipo-Dox) was synthesized. The in vivo tumor targeting capabilities and the therapeutic efficacy were evaluated using the H460 tumor xenografted into mice. To minimize the interactions between the targeted peptide and the surface of the liposome, the amount of PEG on the surface of the liposome was reduced from $5-20 \mathrm{~mol} \%$ (general use) to $1.3 \mathrm{~mol} \%$ of the total lipids. The tumor growth inhibition of the peptide-targeted Lipo-Dox was superior to that of the untargeted Lipo-Dox and to that of the free Dox administered at equivalent doses $(2 \mathrm{mg}$ of doxorubicin $/ \mathrm{kg}$ of body weight), and this result was consistent with the levels of apoptosis measured by TUNEL staining. Near-IR Cy7.5 dye-labeled peptide-conjugated Lipo-Dox also showed a distinct fluorescence signal at the tumor, while the untargeted Lipo-Dox did not show strong signal intensity.

\section{NAPOSOMES}

Recently, Morelli and colleagues developed 'naposomes', multimodal nanoparticles with their external surfaces functionalized by neuroendocrine peptide sequences and that encapsulate both anticancer drugs and metal complexes. ${ }^{48,49}$ Naposomes were obtained by combining an amphiphilic monomer which contains a hydrophobic moiety, a PEG spacer and a peptide, with another monomer based on the same hydrophobic moiety with a chelating agent for metal complexation. Bioactive peptides chosen for naposome assembly (CCK8, ${ }^{50,51} 7-14$ bombesin $(\mathrm{BN})^{52-54}$ and octreotide ${ }^{55-57}$ ) are well-known endogenous (CCK8 and $\mathrm{BN}$ ) or artificial (octreotide) ligands for membrane receptors (cholecystokinin, GRP and somatostatin) that are overexpressed by the cells of several human cancers. Chelating agents, such as DOTA, DTPA and DTPAGlu, are employed to stably complex paramagnetic or radioactive metals for imaging with MRI, PET tomography and scintigraphy (Figure 1). The morphology of aggregates (micelles, liposomes or an open bilayer) is strictly dependent on the starting monomers (the metal complex and/or peptide sequence). The uptake of ${ }^{111} \mathrm{In}$-radiolabeled naposomes by A431 cells overexpressing CCK2-R via transfection was demonstrated by in vitro experiments at $4{ }^{\circ} \mathrm{C}$ and at $37^{\circ} \mathrm{C} .58$ The in vivo biodistribution showed that the overall retention of the radiolabel aggregates in the mice at $18 \mathrm{~h}$ is very high, with essentially no excretion of radioactivity over the observation period. Moreover, the radioactivity retention of the receptor-positive xenografts was always higher than in their respective controls (Figure 1). Finally, in vitro 
a
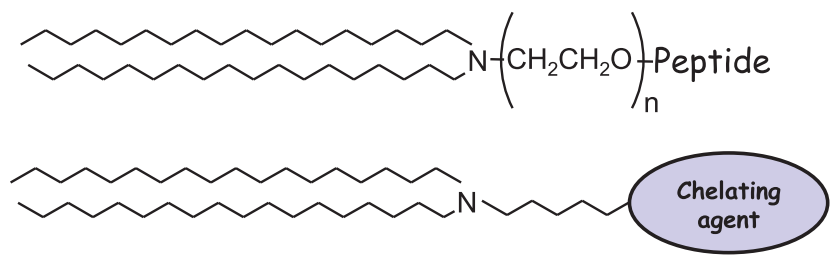

\section{Peptide sequences}

Octreotide:

$$
\text { - DPhe }{ }^{1}-\text { Cys }^{2}-\text { Phe }^{3}-\text { DTrp }^{4}-\text { Lys }^{5}-\text { Thr }^{6}-\text { Cys }^{7}-\text { Thr }^{8}(\mathrm{ol})
$$

[7-14]Bombesin:

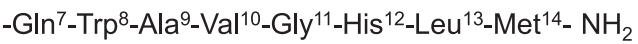

Cholecystokinin (CCK8): - Asp ${ }^{26}-\mathrm{Tyr}^{27}-\mathrm{Met}^{28}-\mathrm{Gly}^{29}-\mathrm{Trp}^{30}-\mathrm{Met}^{31}-\mathrm{Asp}^{32}-\mathrm{Phe}^{33}-\mathrm{NH}_{2}$

\section{Chelating agents:}<smiles>O=C(O)CN1CCN(CC(=O)O)CCN(CC(=O)O)CCN(CC(=O)O)CC1</smiles>

DOTA<smiles>O=C([O-])CN(CCN(CC(=O)[O-])CC(=O)[O-])CCN(CC(=O)[O-])CC(=O)O</smiles>

DTPA<smiles>O=C([O-])CCC(C(=O)[O-])N(CCN(CC(=O)[O-])CC(=O)[O-])CCN(CC(=O)[O-])CC(=O)O</smiles>

DTPAGlu

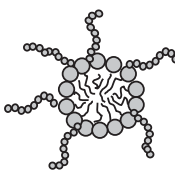

1. Spheric micelles

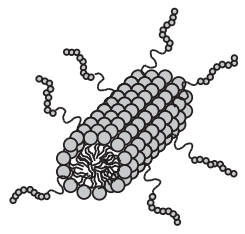

2. Rod-like micelles

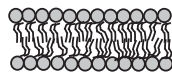

3. Double bilayer

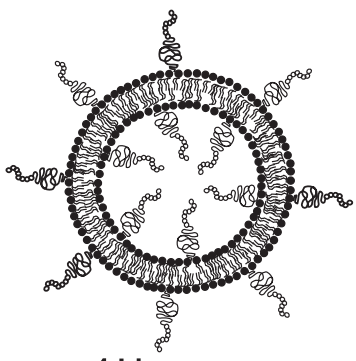

4.Liposomes b

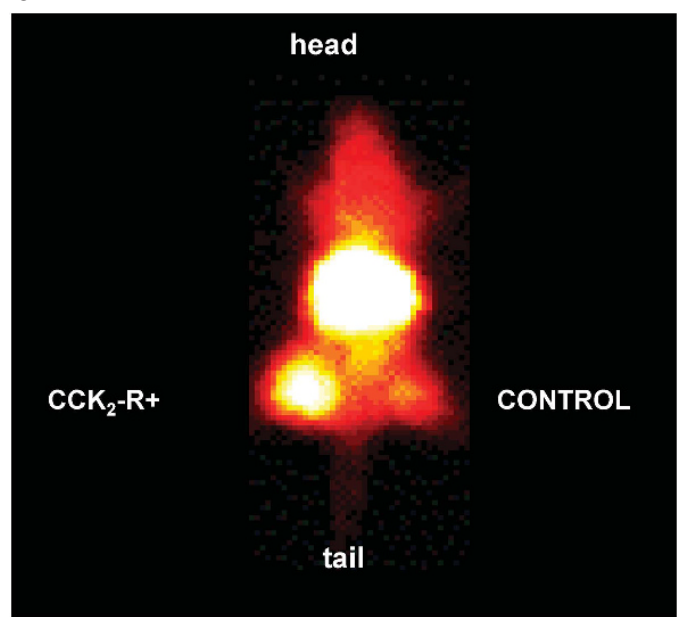

C

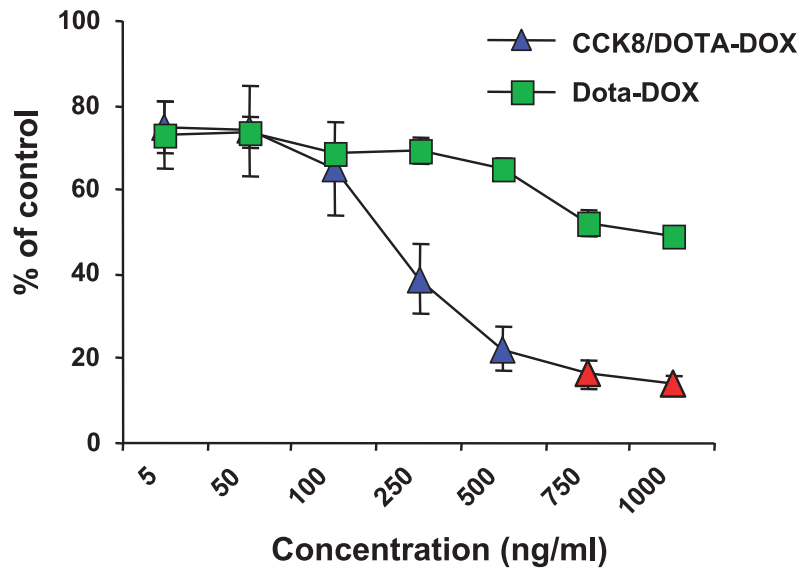

Figure 1 (a) Amphiphilic monomers (one containing a peptide moiety and the other containing the chelating agent) and the supramolecular aggregates that can be obtained when the monomers are combined at the chosen molecular ratio in a water solution. The hydrophobic moieties, present on both monomers, are based on two saturated hydrocarbon chains with 18 carbon atoms. In the two frameworks, the peptide sequences (Octreotide, Bombesin and CCK8) and the structure of the chelating agents used for naposome preparation are reported. The lower part of the figure shows selected results from structural and biological studies on the naposomes labeled with the CCK8 peptide. (b) The $\gamma$-camera image (dorsal view) obtained prior to the dissection of one of the animals $18 \mathrm{~h}$ after injection of the radiolabeled aggregates clearly shows a higher concentration of the radiolabel in the receptor positive xenograft $(+$, left flank) than in the control tumor ( - , right flank). These differences were statistically significant when comparing data from the five animals (paired $t$-test, $P=0.01$ ). (c) The cytotoxicity of liposomal Dox against human carcinoma cells. The A431 cells were incubated with CCK8/DOTA-Dox and with DOTA-Dox at different concentration ranging between 0 and $1000 \mathrm{ng} \mathrm{ml}^{-1}$ at $37^{\circ} \mathrm{C}$. After $8 \mathrm{~h}$, the medium was removed, and after an additional $72 \mathrm{~h}$ an $\mathrm{MTT}$ assay was performed. 
a

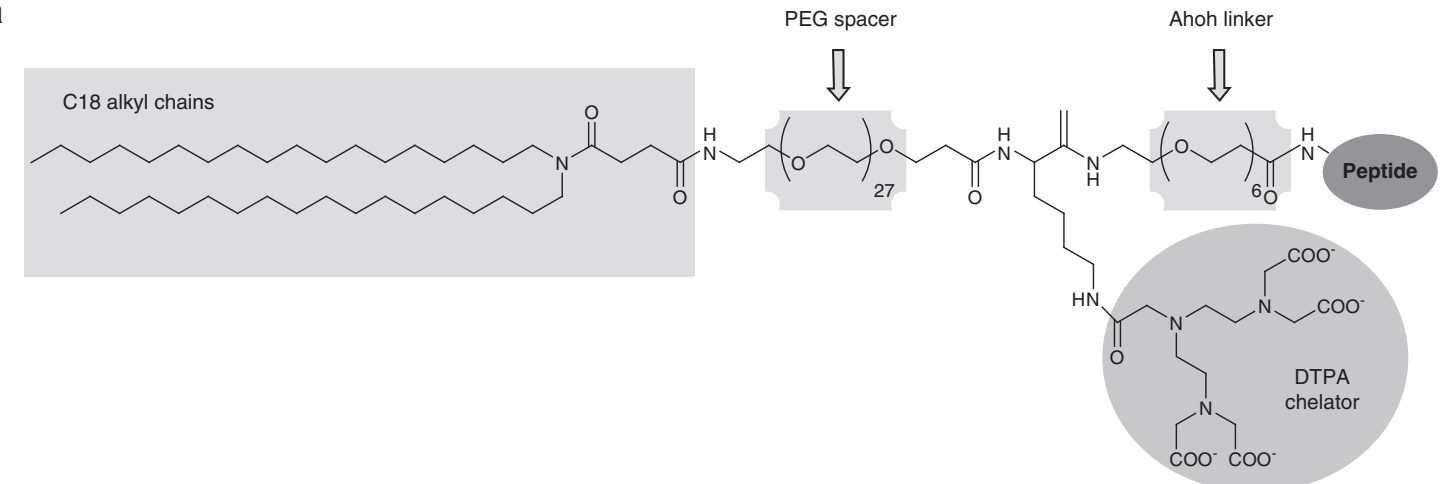

b

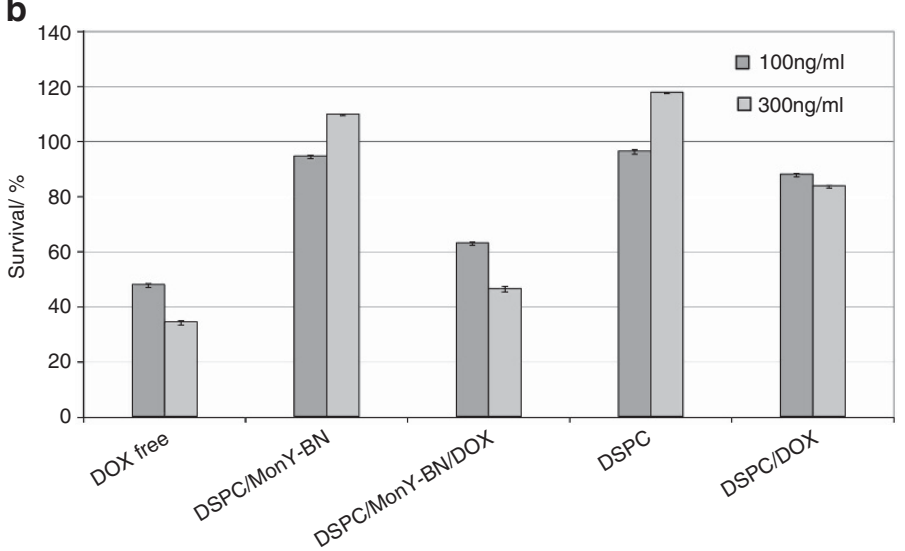

C

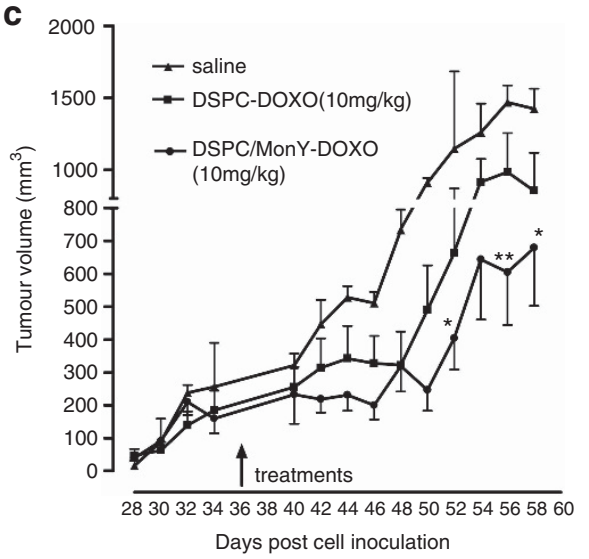

Figure 2 (a) Schematic representation of MonY-BN. The 7-14-BN peptide sequence is reported using the three-letter amino acid code. (b) The cytotoxicity of liposomal Dox against human prostatic cancer cells. The PC-3 cells ( 8000 cells per well) were incubated with DSPC/MonY-BN/Dox, DSPC/Dox and free Dox at $37^{\circ} \mathrm{C}$. The control experiments with free Dox and empty liposomes at the same experimental conditions are reported. After $8 \mathrm{~h}$, the medium was removed, and after an additional $72 \mathrm{~h}$ an MTS assay was performed. (c) Comparative efficacy study on the tumor growth in BALB/c nude mice bearing xenografts (PC-3). Treatment started approximately 5 weeks after cell implantation. Mice $(n=5)$ were administered with i.v. injections of $100 \mu$ l of the liposome suspensions of DSPC/MonY-BN/Dox or DSPC/Dox or with $100 \mu \mathrm{l}$ of HBS buffer (control). The therapeutic efficacy was assessed by measuring the tumor volume (mean \pm s.d.) over time. DSPC/MonY-BN/Dox and DSPC/Dox produce, respective to the saline solution, a tumor growth inhibition (TGI) of 60 and 36\%, respectively. 'Reprinted from Reference 85, Copyright (2012), with permission from Dove Medical Press Ltd.'

cytotoxicity assays were performed by incubating the cells with peptide-containing aggregates filled with Dox. Cell survival in the receptor-expressing cells was significantly lower than in the control. $(\mathrm{C} 18)_{2} \mathrm{DOTA} /(\mathrm{C} 18)_{2} \mathrm{~L} 5 \mathrm{CCK} 8$ (90/10) liposomes showed comparable results. ${ }^{59}$

Very recently, the same authors described new BN-conjugated nanosystems for theranostic purposes. ${ }^{60}$ The liposomes are based on the co-aggregation of a DSPC phospholipid with MonY-BN, a new synthetic amphiphilic monomer (Figure 2) containing a 7-14-Bombesin peptide fragment, DTPA chelating agent, hydrophobic moiety with two C18 alkyl chains, and PEG spacers. ${ }^{111}$ In-labeled liposomes loaded with doxorubicin (DSPC/MonY-BN in a 97/3 molar ratio) showed a higher specific binding to PC-3 (prostate cancer) cells than the peptide free DSPC liposomes $(2.7 \pm 0.3$ and $1.4 \pm 0.2 \%)$ and showed significant growth inhibition at drug amounts of $100 \mathrm{ng} \mathrm{ml}^{-1}$ and $300 \mathrm{ng} \mathrm{ml}^{-1}$. Moreover, the intravenous treatment of PC-3 xenograft-bearing mice using targeted liposomes and untargeted liposomes at a $10 \mathrm{mg} \mathrm{kg}^{-1}$ Dox dose produced a higher tumor growth inhibition (60 and 36\%, respectively) compared with the control animals.

\section{POLYMERIC MICELLES}

Large proportions of new drug candidates emerging from highthroughput drug screening initiatives are water-insoluble. To overcome the poor solubility of certain drugs, the development of pharmaceutical carriers such as micelles and polymeric micelles was suggested.

Polymeric micelles are nanosized particles obtained from the selfassembly of biocompatible amphiphilic block copolymers in aqueous solution. ${ }^{61}$ Their characteristic feature is a pronounced core-shell architecture, which can be controlled by the individual polymer blocks. The core of polymeric micelles is typically obtained from a hydrophobic segment that consists of biodegradable polyesters, such as poly(glycolic acid), poly(D,L-lactic acid) (PDLLA), $\operatorname{poly}(\varepsilon-$ caprolactone) (PCL), and poly(L-aspartic acid). ${ }^{62}$ Additionally, the largely used corona forming polymer is polyethylene glycol (PEG), with a molecular weight ranging from 2 to $15 \mathrm{kDa}$. The hydrophobic core represents an ideal carrier environment for poor water-soluble drugs while the hydrophilic shell provides interactions with the solvent, protecting the hydrophobic core from the aqueous bulk phase. The hydrodynamic radius of polymeric micelles, usually ranging between 10 and $100 \mathrm{~nm}$, can be controlled by varying the hydrophobic block of the copolymer. ${ }^{63}$

An example of theranostic micelles that can be used for tumor treatment and for MRI detection was successfully obtained by Boyes and colleagues through the attachment of well-defined, multifunctional polymer chains to gadolinium metal-organic framework 
<smiles>C=CCOC(C)C(=O)OCC(C)OC(=O)C(C)O</smiles>

AP-PEG-PLA
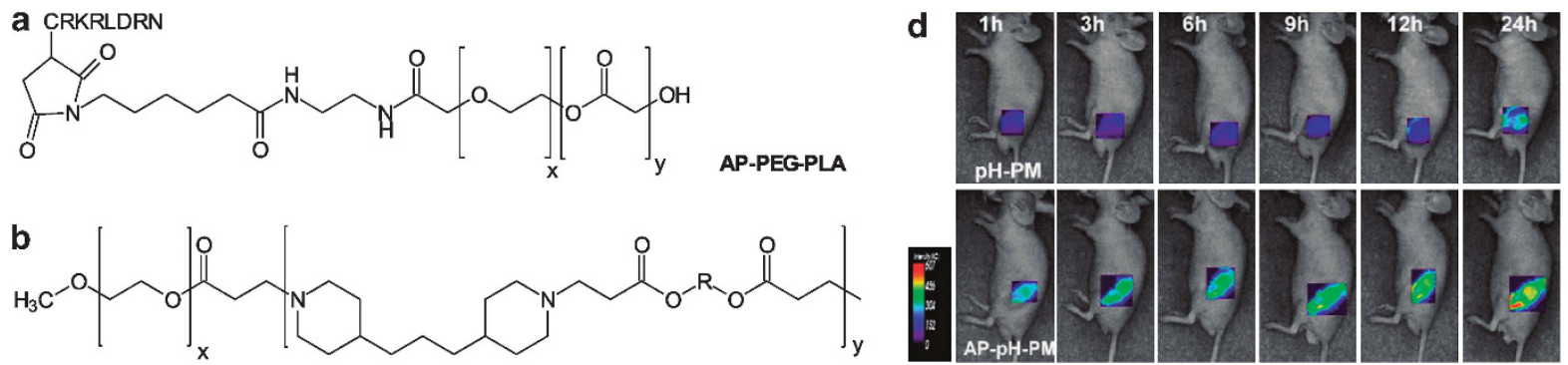
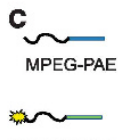

AP-PEG-PLA

Doxorubicin
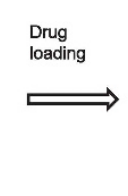
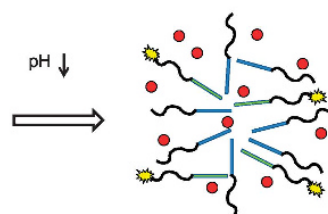
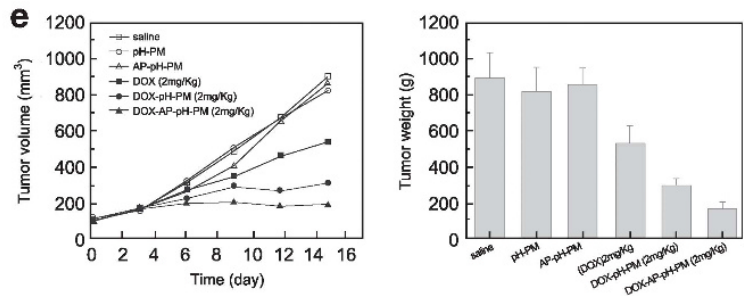

Figure 3 Design strategy of a peptide-conjugated pH-responsive micelle. (a) Chemical structure of the tumor-targeting AP peptide coupled PEG-PLA block copolymer (AP-PEG-PLA) and (b) of the pH-responsive MPEG-PAE block copolymer (MPEG-PAE). (c) Schematic diagram depicting tumor-targeting and pH-responsive polymeric micelles of AP-PEG-PLA/MPEG-PAE (AP-pH-PM), which triggered Dox release due to the sharp pH-dependent micellization/ demicellizaton transition at the tumoral acidic $\mathrm{pH}$. (d) In vivo fluorescence images of MDA-MB-231 tumor xenografted athymic nude mice injected with TRITC-pH-PM and with TRITC-AP-pH-PM. (e) In vivo anti-tumor therapy of doxorubicin encapsulated micelles: in vivo anti-tumor therapeutic efficacy of saline ( $\square)$, pH-PM (O), AP-pH-PM $(\Delta)$, free Dox $\left(2 \mathrm{mg} \mathrm{kg}^{-1}\right)(\boldsymbol{\square})$, Dox- $\mathrm{pH}-\mathrm{PM}$ with $2 \mathrm{mg} \mathrm{kg}^{-1}$ of Dox $(\bullet)$, and Dox-AP-pH-PM with $2 \mathrm{mgkg}-1$ of Dox $(\mathbf{\Delta})$. Values represent the mean \pm s.d. and the tumor weights of MDA-MB-231 tumor-bearing mice 15 days post-treatment. Reproduced with permission from the publisher [68].

(MOF) nanoparticles. Gd MOF nanoparticles were surface modified by the covalent attachment of well-defined polymers containing both a targeting peptide (GRGDS- $\mathrm{NH}_{2}$ ) and the antineoplastic agent methotrexate (MTX) to produce a novel theranostic nanodevice. ${ }^{64}$ To evaluate the potential of the copolymer-modified nanoparticles for use as a theranostic nanodevice, MRI, fluorescence imaging, and cell growth inhibition studies were performed. In the MRI studies, the T1 relaxation times of the polymer-modified Gd MOF nanoparticles are on the same order of magnitude as those of the conventional clinically used Gd contrast agents. Copolymer-modified Gd MOF nanoparticles containing the targeting moiety GRGDS- $\mathrm{NH}_{2}$ showed active targeting of FITZ-HSA tumor cells, which overexpress $\alpha v \beta_{3}$ integrins. The Gd MOF nanoparticles modified with the copolymer containing MTX showed a dose-dependent treatment of FITZ-HSA cancer cells, determined by cell viability measurements.

Very recently, multifunctional micelles decorated with the cRGD peptide were also investigated for PET imaging by Gong and colleagues. They synthesized and characterized multifunctional unimolecular micelles made from hyperbranched amphiphilic block copolymers [H40-P(LG-Hyd-Dox)-b-PEG] conjugated with the cRGD peptide and with the macrocyclic chelator NOTA for cancertargeted drug delivery and for PET imaging. ${ }^{65}$ In the multifunctional micelles, the anticancer doxorubicin drug is bound to the hydrophobic poly(L-glutamate) segment $\mathrm{P}$ (LG-Hyd-Dox) with a hydrazone linkage. This acid-labile linkage provides a $\mathrm{pH}$-controlled drug release behavior for the micelles. The active tumor targeting ligand (cRGD) and the PET isotope chelator NOTA were conjugated onto the PEG arms. From a biological point of view, the cytotoxicity assays showed a higher cellular uptake in the U87MG human glioblastoma cells of the target selective micelles (H40-Dox-cRGD) than in the cells of the non-targeted micelles (H40-Dox). Moreover, in vivo studies of tumor-bearing mice confirmed that H40-DoxcRGD- ${ }^{64} \mathrm{Cu}$ exhibited a much higher level of tumor accumulation than $\mathrm{H} 40-\mathrm{Dox}-{ }^{64} \mathrm{Cu}$, as measured by non-invasive PET imaging and by ex vivo fluorescence imaging.

Polymeric micelles were also used for the detection of an atherosclerotic lesion by Rhee $\mathrm{K}$ and colleagues. They developed hydrophobically modified chitosan nanoparticles (CNPs) chemically conjugated with an atherosclerotic plaque-homing peptide (CRKRLDRNC; AP peptide) and with Cy5.5, a near-infrared (NIR) probe. The AP peptide, discovered using an in vivo phage display screening method, ${ }^{66}$ could adhere to atherosclerotic plaque by binding to the interleukin (IL)-4 receptors on the macrophages, endothelial cells, and smooth muscle cells. The conjugated CNPs demonstrated a higher binding affinity to the tumor necrosis factor (TNF)-R-activated bovine aortic endothelial cells (BAECs) than to the non-activated BAECs. ${ }^{67}$ Moreover, in vivo NIRF imaging data revealed that larger amounts of the APCy5.5CNPs were bound to atherosclerotic lesions in the atherosclerotic mouse that lacks the lowdensity lipoprotein receptor than to the same lesions in a normal mouse (Figure 3). Additionally, the same authors prepared $\mathrm{pH}$ responsive polymeric micelles (AP-pH-PMs) decorated with the AP peptide and loaded with the chemotherapeutic agent doxorubicin for breast cancer disease. The micelles were made fluorescent by adding a small amount of a fluorescent dye (TRITC) into their composition. This modification was utilized to evaluate in vitro and in vivo the binding capability of the AP-pH-PMs with respect to the MPEG-PAE, where the peptide is absent. The in vivo cytotoxicity studies on the MDA-MB231 human breast tumor-bearing mice demonstrated the excellent anticancer therapeutic efficacy of the targeted Dox-AP-pHPMs with respect to the free Dox and to the Dox encapsulated MEGPAE micelles. ${ }^{68}$

\section{POLYMERIC MICELLES WITH A SOLID CORE}

Most polymeric micelles are constructed around a solid core, which display unique properties for the stability and/or the detection of the 
a

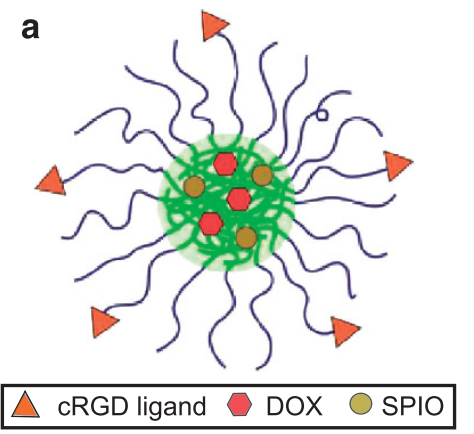

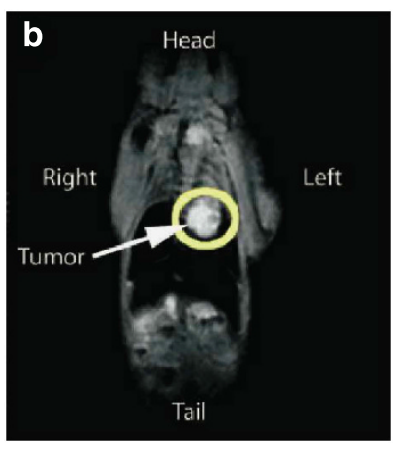

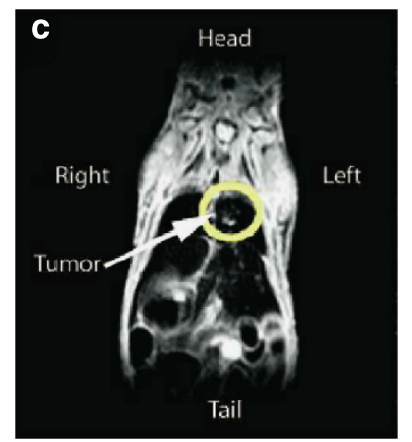

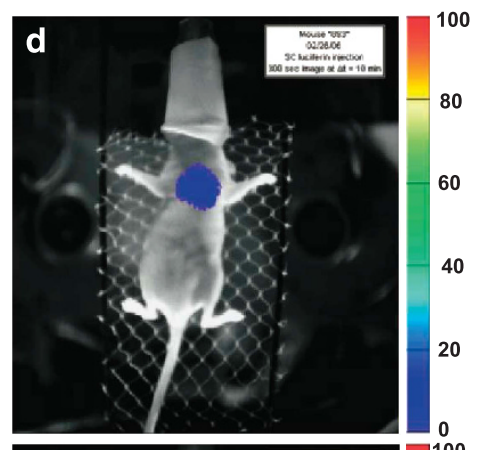
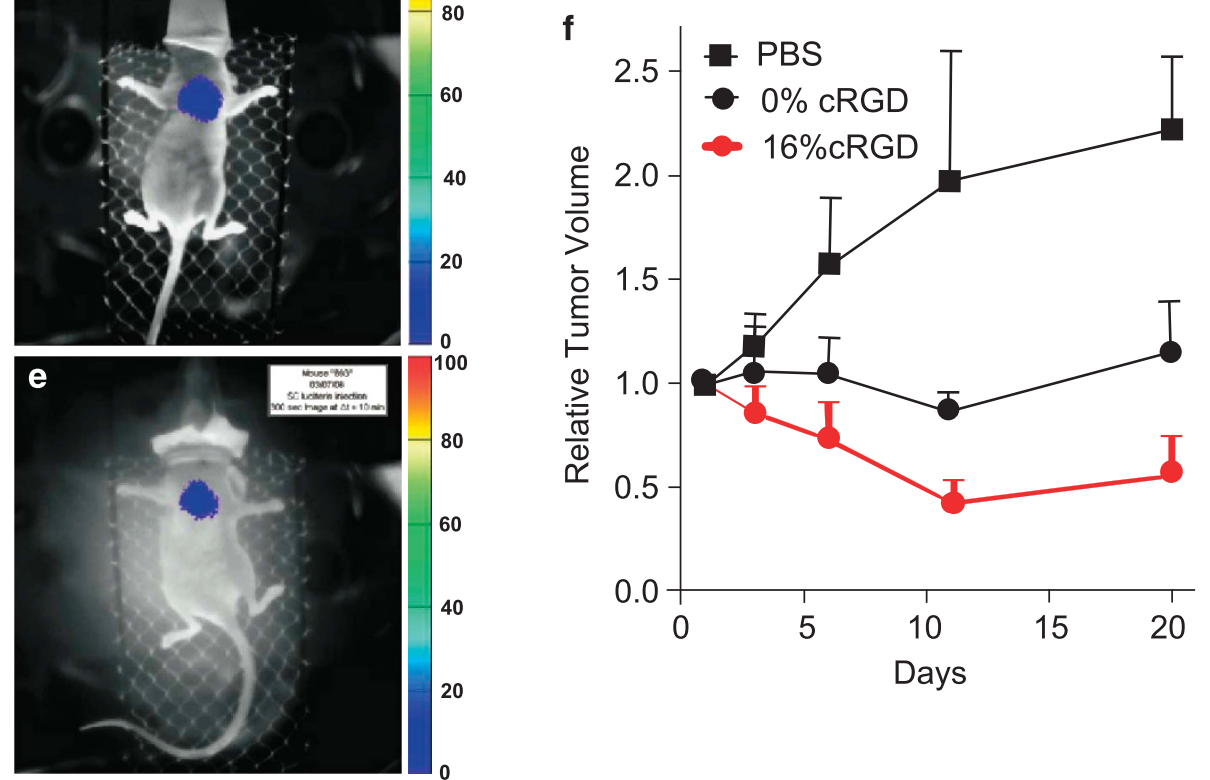

Figure 4 (a) Schematic of a multifunctional polymeric micelle. (b) and (c) Pre- and post-contrast coronal images of tumor-bearing mice by T2-weighted imaging (TR/TE $=4 \mathrm{~s} / 40 \mathrm{~ms}$ ), respectively. (d) and (e) Bioluminescence imaging of a mouse bearing luciferase-transfected $\mathrm{H} 1299$ xenograft at days 0 and 7 , respectively. Dox-loaded, $16 \%$ cRGD-micelles were injected into the tail vein at days 0 and 3 ( $4 \mathrm{mg} \mathrm{kg}^{-1}$ Dox dose each time). (f) Antitumor efficacy data for the PBS control and Dox-SPIO micelles with 0 and 16\% surface density of CRGD in subcutaneous A549 tumor xenografts in nude mice. Each data point is averaged from three animals. Copyright@ Experimental Biology and Medicine.

system. Core nanoparticles, typically ranged between 5 and $100 \mathrm{~nm}$ in diameter, and nanoparticles of many different shapes and composite formulations have been developed. The most extensively studied core nanoparticle materials are based on metals, such as gold, silver, iron, cobalt, nickel and platinum. Nanoparticles such as iron oxide, quantum dots, and gold are known to offer extraordinary features for diagnostics as well as for therapeutics. Imaging modalities, such as optical imaging, MRI, and surface plasmon resonance (SPR), are rapid, noninvasive techniques that have been used in cancer therapy where the early detection and disease prognosis need to be improved.

\section{IRON OXIDE NANOPARTICLES}

Iron oxide nanoparticles are clinically approved MRI contrast agents and have also been proposed as a platform for the development of targeted contrast agents because they have a large surface area that can be functionalized with different targeting ligands, their blood circulation can be modulated according to their physicochemical properties, and contrast agents and drugs can be included at predetermined ratios either in the interior or on the surfaces of the nanoparticles.
One of the first examples of polymeric micelles with an iron oxide core was reported by Ross and colleagues in 2006 as a versatile drug delivery vehicle for the supply of imaging and therapeutic agents to a brain cancer milieu. The authors prepared nanoparticles based on a polyacrylamide (PAA) nanoparticle core that combine a magnetic resonance imaging contrast enhancement, photodynamic therapy and specific targeting to tumor sites by using the F3 vascular homing peptide. The F3 peptide, a 31-amino acid fragment of a high mobility group protein, was shown to home in on the vasculature of a number of tumor types by directly interacting with endothelial cells. ${ }^{69}$ The F3-targeted polymeric nanoparticle formulation consists of encapsulating iron oxide or a fluorescent probe and a Photofrin photosensitizer. ${ }^{70}$ This formulation was evaluated using a series of in vitro experiments to study its ability to produce singlet oxygen, to target the nucleolin cell surface receptor, and to confer photosensitivity. The in vitro studies revealed that the F3-targeted nanoparticles were bound, internalized, transported, and concentrated within the tumor cell nuclei. Photoactivation of the nanoparticles resulted in the loss of cell viability. The in vivo studies revealed that iron oxide/Photofrin-encapsulated F3-targeted nanoparticles could 
be detected in i.c. 9L gliomas using MRI. Treatment of gliomabearing rats with the F3-targeted nanoparticles followed by photodynamic therapy (PDT) showed a significant improvement in the survival rate when compared with animals that received PDT after administration of the non-targeted nanoparticles or of systemic Photofrin. In this formulation, the micelles homed in on the vasculature of a number of tumor types through the interaction of the F3 peptide with endothelial cells. This peptide exhibits two attractive features compared with the RGD containing peptide: (1) the RGD peptide needs to be cyclized to be functional, which is not optimal for large scale studies, while the F3 peptide does not have this requirement. (2) In some human cancers, the F3 peptide can interact directly with the tumor cells, where it is specifically taken up at the cell surface, internalized into the cell and transported to the nucleus. Cell surface nucleolin is a specific marker for angiogenic endothelial cells within the tumor vasculature. Nevertheless, many authors chose to functionalize theranostic nanoparticles with RGD or with RGD analogs due to their capability to selectively recognize $\alpha_{\mathrm{v}} \beta_{3}$ integrin receptors on angiogenic endothelial cells that are overexpressed in many solid tumors (colon cancer, brain cancer, prostate cancer and others).

For example, in 2006 Gao and colleagues developed multifunctional polymeric micelles decorated with cRGD (cRGD-DOXO-SPIO) with a cancer-targeting capability for controlled drug delivery and for efficient MRI contrast characteristics. These micelles are composed of the chemotherapeutic agent DOXO, which is released from polymeric micelles through a $\mathrm{pH}$-dependent mechanism, and of a cluster of super paramagnetic iron oxide (SPIO) nanoparticles $(8 \mathrm{~nm}$ in diameter). SPIO and DOXO were loaded into the polymeric micelles at 6.7 and $2.7 \mathrm{w} / \mathrm{w} \%$, respectively. Amphiphilic block copolymers of MAL-PEG-PLA and MPEG-PLA were used for micelle formation. Different amounts of MPEG-PLA were used to control the density of maleimide, which ultimately determined the density of cRGD on the micelle surface ( 0 and $16 \%$ for all PEG chains). In vitro imaging of the multifunctional micelles was evaluated using $\alpha v \beta_{3}$-expressing SLK tumor endothelial cells (derived from human Kaposi's sarcoma) by MRI, by flow cytometry and by confocal laser scanning microscopy. Moreover, cRGD micelles showed a higher cell growth inhibition than the untargeted micelles. ${ }^{71}$ The tumor targeting, imaging ability, and antitumor efficacy of the multifunctional micelles were validated using in vivo assays (Figure 4). For the antitumor efficacy in the orthotopic H1299 tumor model, bioluminescent imaging (BLI) of tumors transfected with the firefly luciferase gene was used. A comparison between the target selective and untargeted SPIO micelles showed a size reduction in the tumor of approximately $50 \%$ after 7 and 10 days, respectively. In the mice treated with the PBS control group the tumor size almost doubled after 10 days. $^{72}$ In a separate study, these multifunctional micelles (MFM, formed by MAL-PEG-PLA and MPEG-PLA copolymers, $75 \%$ by weight) containing Dox and SPIO were decorated with a RGDLATLRQL (LCP) peptide, which binds specifically to the $\alpha v \beta 6$ receptors that are overexpressed in lung cancer cells. Different surface densities were obtained by varying the molar fraction of MAL-PEG-PLA between 20 and $40 \%$. The selective binding ability of the LCP peptide to the $\alpha \mathrm{v} \beta 6$ receptors with respect to MFM derivatized with a scrambled peptide (SP) sequence was evaluated using comparative exposures of H2009 cells studied using $[3 \mathrm{H}]$ radioactivity measurements, confocal microscopy and MRI. $\alpha$ v 36 -negative H460-cells were used as a control. The resulting LCP-encoded MFM showed a superb T2 relaxivity for ultrasensitive $\mathrm{MR}$ detection and an increased cytotoxicity in $\mathrm{H} 2009$ cells compared with the SP-encoded MFM. ${ }^{73}$
As an alternative, theranostic nanoparticles based on oil-in-water nanoemulsions and functionalized with the $\alpha v \beta_{3}$-specific RGD peptide were developed and evaluated in a colon cancer mouse model. The nanoparticles (PEG-DSPE:DSPC:MAL-PEG-DSPE molar ratio 0.83:1:0.1) contained iron oxide nanocrystals for MRI, the fluorescent dye Cy7 for NIRF imaging, and the hydrophobic glucocorticoid prednisolone acetate valerate (PAV) for therapeutic purposes. in vitro and in vivo assays confirmed that the angiogenesistargeted nanoemulsions showed efficient tumor growth inhibition with respect to the untargeted nanoemulsions. ${ }^{74}$

Ruoslahti and colleagues described a self-amplifying nanoparticledelivery system (nanomag-D-SPIO) functionalized with tumor-homing pentapeptide CREKA (Cys-Arg-Glu-Lys-Ala) ${ }^{75}$ for the effective detection of tumors in prostate blood vessels.

The CREKA peptide exposed on the nanoparticles (DSPC/Chol/ DOGS-NTA at a molar ratio of 57:37:10) recognizes the clotted plasma proteins near tumor vessel walls or the tumor stroma and induces localized tumor clotting. Additionally, they reported a study on elongated nanoworms (NW) coated with another tumor-homing peptide, CRKDKC. The same authors prepared a nanosystem functionalized with the N/C $\alpha$-methylated CREKA peptide (CR(NMe)EKA) to increase the stability of the peptide in circulation. ${ }^{76}$ Mice bearing two orthotopic human prostate cancer xenograft tumors (22Rv1 and LAPC29) were treated with the nanoworms. Mice treated with the targeted nanoworms showed extensive clotting in the tumor vessels, while no clotting was observed in the vessels of normal tissue. Diagnostic studies performed using optical and magnetic resonance imaging confirmed the ability of the targeted nanoworms to accumulate on the tumor vessels, and ultrasound imaging showed a reduced blood flow in the tumor vessels. In vivo studies carried out on mice with prostate cancer demonstrated that both CRKDKC-PEGNW and CR(NMe)EKA-PEG-NW are able to induce tumor necrosis ( $\sim 70 \%)$ when treated with multiple doses.

NWs were also proposed for transient tumor regression in glioblastoma multiforme (GBM) endothelium. ${ }^{77}$ Treatment of malignant brain tumors is one of the most formidable challenges in oncology due to the difficulties associated with drug delivery across the BBB to the tumor. The brain tumor endothelium, with characteristics such as a high proliferation, high permeability, and high expression of proangiogenic factors, can be treated with antiangiogenic approaches. ${ }^{78}$ These nanosystems combined three different functions: (i) the CGKRK peptide able to specifically target the mitochondria of the tumor endothelial cells and tumor cells, (ii) the ${ }_{\mathrm{D}}[\mathrm{KLAKLAK}]_{2}$ proapoptotic peptide that acts on the mitochondria, and (iii) iron oxide nanoparticles, which enhance the proapoptotic activity. Moreover, with the help of a tumor penetrating peptide (iRGD), the NWs were capable of infiltrating the tumor tissue for tumor cell eradication after extravasation. This strategy was evaluated in the lentivirus-induced, transplantable, and orthotopic brain tumor models. The tumor accumulation and the binding capability of the single peptide was not compromised by the chimeric NWs composed of the CGKRK and ${ }_{D}[\text { KLAKLAK }]_{2}$ peptides. Complete tumor ablation was achieved in the first model and the significant prolongation of survival was observed in the latter two models, indicating promise for eventual clinical application.

In vivo brain tumor targeting was also achieved by Zhang and colleagues using a magnetic/optical nanoprobe with the chlorotoxin (CTX) peptide. ${ }^{79}$ CTX shows strong affinity for tumors of neuroectodermal origin and is able to permeate across an intact BBB. ${ }^{80}$

Superparamagnetic iron oxide nanoparticles coated with oleic acid and with PEG (NP-SH) were modified with an amine group-blocked 
polyethyleneimine (PEI) to act as a $\mathrm{pH}$-sensitive coating layer. Both anti-GFP siRNA and CTX were immobilized onto the NPs as a therapeutic moiety and as a targeting ligand for glioma, respectively. In vitro studies carried out on C6 glioma cells demonstrated that the nanoprobes decorated with CTX only possess significant cytotoxic activity and gene silencing effects at acidic $\mathrm{pH}$ conditions.

Another example of polymeric micelles built around iron oxide (cross-linked dextran-coated superparamagnetic iron oxide nanoparticles) was reported by Medarova and colleagues They synthesized a nanoshuttle functionalized with EPPT peptides (MN-EPPT-siBIRC5) for the specific delivery of a synthetic siRNA to the tumor-specific antigen underglycosylated mucin-1 (uMUC-1), which is found in $>90 \%$ of human breast adenocarcinomas. In this nanoshuttle, there are two diagnostic agents: SPIONs for tumor detection by MRI and the Cy5.5 dye for near-IR optical imaging. ${ }^{81}$ This therapeutic and diagnostic nanodrug exhibited superparamagnetic and fluorescence properties and was simultaneously imaged in vivo by T2 MRI and by near-IR optical imaging. The systemic administration of the nanodrug once a week for 2 weeks induced considerable levels of necrosis and apoptosis in the tumors as a result of the siBIRC5-mediated inhibition of the antiapoptotic survivin proto-oncogene, which translates into a significant decrease in the tumor growth rate. This tumor-targeted, imaging-capable nanodrug highlights the potential for MRI-guided tumor treatment, which can be used to quantify changes in the tumor volume over the treatment schedule and to guide the selection of an optimal treatment course.

\section{GOLD NANOPARTICLES}

Gold nanoparticles have been utilized extensively because of their easy detection by electron microscopy, their SPR properties, and their photothermal effects.

Bhatia and colleagues designed communicating nanosystems using 'signaling' modules (gold nanorods, NRs; or the tumor-targeted tissue factor, tTF) as selective tumor-activating agents and using 'receiving' nanoparticles (magnetofluorescent iron oxide nanoworms, NWs; or Dox-loaded liposomes, LPs) as targeted imaging or therapeutic agents. ${ }^{82} \mathrm{NWs}$, which were previously developed by Bhatia and colleagues, are elongated nanostructures formed from the assembly of iron oxide cores that exhibit strong magnetic properties and efficient tumor targeting. ${ }^{83}$ The two 'signaling' modules specifically activated the coagulation cascade in the tumor to broadcast the tumor's location to the receivers in circulation. The NRs passively targeted the tumors and converted external electromagnetic energy into heat to locally disrupt the tumor vessels. The tTF, which included the RGD peptide motif, induced coagulation upon binding to the angiogenic $\alpha v \beta_{3}$ receptors. The receiving nanoparticles targeted the regions of coagulation. The NWs and LPs were derivatized with a peptide substrate for the coagulation of transglutaminase FXIII or with a fibrin-binding peptide. After injecting the signaling modules into MDA-MB- 435 bearing mice at $45^{\circ} \mathrm{C}$, the 'receiving' NWs or LPs indicated prominent extravascular accumulation around the tumor and amplified the therapeutic outcome, demonstrating a heatdependent increase in the passive accumulation and in the specific biochemical recognition of the coagulation process. Communication via the coagulation cascade improved the accumulation of the receiving modules on the tumors by a factor of 40 relative to the accumulation of the receiving modules without communication.

\section{QUANTUM DOTS (QDS)}

Another commonly studied core nanoparticle is the 'quantum dot', named for its unique optical properties and high quantum yield. ${ }^{84}$
QDs are semiconductor materials consisting of elements from groups II to VI in the periodic table, such as $\mathrm{Cd}, \mathrm{Zn}$, and Se, or from groups III-V, such as In, P, and As. ${ }^{85}$ By confining the electrons to various sizes, the energy band gap, absorption spectra and corresponding emission wavelengths can be tuned from the ultraviolet (UV) to the NIR region. The quantum yield of the semiconductor (for example CdSe) core is enhanced by the addition of a shell of a high band-gap semiconductor material, for example zinc sulfide $(\mathrm{ZnS})$, around the core. The hydrophilicity/hydrophobicity properties of QDs can be altered by modifying their surfaces. For example, carboxylic groups on the $\mathrm{ZnS}$ shell can be converted into thiol groups $(\mathrm{SH})$. The exceptional brightness and photostability of QDs compared with conventional organic dyes as well as the different emission spectra for quantum dots of the same nanomaterials with different sizes are the reasons for using QDs as fluorescent nanosystems for imaging tumors.

QDs emitting in the NIR region and covered by PEGylated phospholipid micelles were used as optical probes for in vivo imaging of solid tumors. Target selective nanosystems were obtained by functionalizing micelles with the cyclic-RGD peptide for targetspecific labeling of tumors in mouse models bearing pancreatic tumor xenografts, which were implanted both subcutaneously and orthotopically. Co-encapsulation of both the QDs and anticancer drugs in the phospholipid micelles were also demonstrated, showing the potential for engineering theranostic nanoparticles for advanced biological applications. In vitro viability studies on Panc- 1 cells were performed, treating the cells with the micelles co-encapsulating the QDs and $2.0 \mathrm{wt} \%$ of Dox as well as with the micelles encapsulating the QDs only (control). The viability of the Panc-1 cells treated with the drug-loaded particles decreased dramatically, thus confirming the toxic effect of the Dox released from the particles on the human cancer cells. ${ }^{86}$

\section{MESOPOROUS SILICA PARTICLES}

Nanoporous silica offers a higher surface area and binding capacity for therapeutic and diagnostic agents than similarly sized liposomes and, therefore, provides an attractive drug delivery system. Multicomponent cargos are easily loaded into the nanoporous silica cores, and the resultant nanocarriers can potentially be used for targeted multicomponent delivery.

In 2010, Lo and colleagues developed tri-functionalized mesoporous silica nanoparticles (MSNs) for use as theranostic (imaging/ targeting/therapy) compounds. ${ }^{87}$ The mesoporous silica materials consisted of highly ordered, hexagonal mesoporous silica structures with three distinct domains: the silica framework, the hexagonal nanochannels/pores, and the nanoparticle's outer surface. The authors incorporated a near-infrared fluorescent contrast agent for imaging of the nanoparticles, ATTO647N, and an oxygen-sensing, palladiumporphyrin based photosensitizer (Pd-porphyrin; PdTPP) for photodynamic therapy (PDT) in the silica framework of the MSNs and in the MSN's nanochannels, respectively. Finally, cRGDyK peptides were conjugated to the outer surfaces to target the overexpressed $\alpha v \beta_{3}$ integrins of the cancer cells (Figure 5). Cellular uptake experiments were conducted with two tumor cell lines: MCF-7 (breast cancer), which is $\alpha_{\mathrm{v}} \beta_{3}$ integrin deficient, and U87-MG (glioblastoma), which overexpresses the $\alpha_{\mathrm{v}} \beta_{3}$ integrin receptors. Confocal fluorescence microscopy confirmed the internalization of the RGD-labeled MSNs via receptor-mediated endocytosis. Flow cytometric analyses revealed no significant MSN fluorescence from the U87-MG cells pre-treated with various concentrations of the blocking agent $c\left(\right.$ RGDyK). These results indicate the $\alpha_{v} \beta_{3}$ integrin- 
a

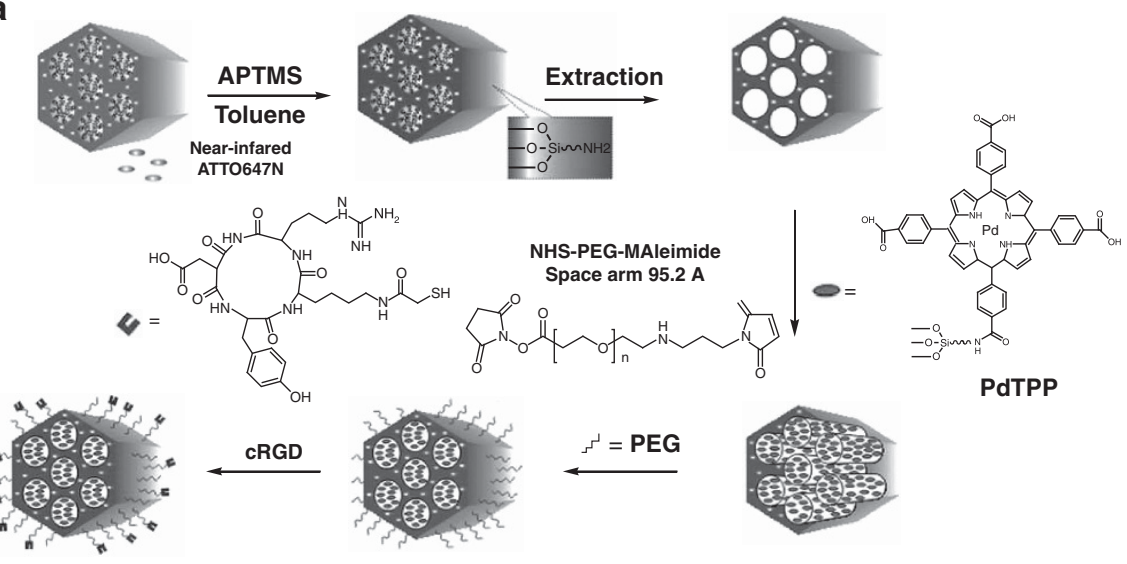

b

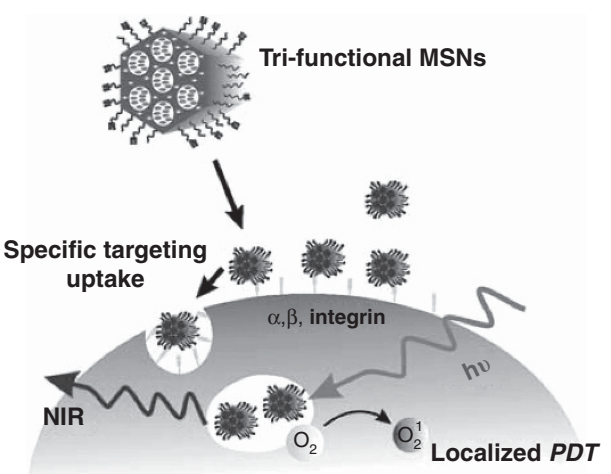

Figure 5 (a) Schematic representation of the tri-functionalized MSN A647@MSN-RGD-PdTPP obtained by sequential functionalization with the following: (i) the contrast agent (ATT0647N), (ii) the PDT photosensitizer agent (APTMS-PdTPP), and (iii) the tumor targeting ligand (cRGD); (b) theranostic MSNs possessing separate domains for traceable imaging, localized PDT photosensitizers, and efficient targeted-delivery. Reproduced with permission from the publisher [87].

dependent uptake of the A647@MSN-RGD-PdTPP nanoparticles by the U87-MG cells. Finally, the therapeutic potential of tri-functionalized MSNs was confirmed using PI (propidium iodide) staining and a WST-1 assay. These experiments showed a significant difference in the post-irradiation cytotoxic response of the U87-MG cells that had been treated with the targeted MNPs with respect to the cells treated with the untargeted MNPs, while the MCF-7 cell survival was $~ 80 \%$ after irradiation for the same concentration of nanoparticles.

Very recently, Ashley and colleagues reported an interesting nanocarrier construct, the protocell $(100-150 \mathrm{~nm}$ in diameter), that synergistically combines features of mesoporous silica particles and liposomes. They were synthesized by the liposome fusion to the highsurface-area spherical silica particles. ${ }^{88}$ The protocells were decorated with SP94 peptides $\left(\mathrm{H}_{2} \mathrm{~N}\right.$-SFSIIHTPILPLGGC-COOH), which were identified from a filamentous phage display to have an affinity for unknown receptor(s) expressed by human hepatocellular carcinoma (HCC), and with $0.500 \mathrm{wt} \%$ of a histidine-rich fusogenic peptide $\left(\mathrm{H}_{5} \mathrm{WYG}\right)$, which promotes the endosomal escape of the protocells and the cytosolic dispersion of the encapsulated cargo. The nanoporous support resulted in greater stability and in enhanced lateral bilayer fluidity compared with both liposomes and non-porous particles, thereby promoting multivalent interactions between the protocell and the target cancer cell using a minimal number of targeting peptides via peptide recruitment to the cell surface. Protocells composed largely of DOPC and loaded with fluorescent probes (calcein, an Alexa Fluor 647-labeled dsDNA oligonucleotide, a red fluorescent protein and $\mathrm{Cd} / \mathrm{Se}$ quantum dots) and with a chemotherapeutic drug (Dox) have a high specific affinity $\left(K_{\mathrm{d}}\right.$ $<1 \mathrm{~nm}$ ) for HCC cells, and, over the range of 6-2 peptides per particle, their Kd values are consistently low (0.94-0.08 nM) and relatively independent of the peptide density. Protocells, owing to the high surface area and to the porosity of their nanoporous cores, have an 1000 times higher capacity for Dox than similarly sized liposomes (loaded through an ammonium phosphate gradient-based approach) and can be engineered to release nearly $90 \%$ of their encapsulated Dox in a bioactive form using endocytosis onto HCC. Additionally, DOPC protocells exhibit long-term stability when maintained in a simulated body fluid ( $\mathrm{pH}$ of 7.4 ) at $37^{\circ} \mathrm{C}$, while exposing protocells to a buffer with a $\mathrm{pH}$ of 5.0 promoted the rapid release of drugs $(99 \%$ within $12 \mathrm{~h}$ ). Cell viability tests indicated that the Dox-loaded protocell treatment maintained greater than 90\% normal hepatocyte viability while killing nearly $97 \%$ of the MDR $1+$ hepatocellular carcinoma (Hep3B). In contrast, Dox-loaded liposomes or protocells without fluidity on their surface were less efficient at killing Нер3B and caused considerable cytotoxicity to non-cancerous cells. The Dox-loaded protocells demonstrated good therapeutic ability compared with both the free Dox and Dox-loaded liposomes.

\section{CONCLUSIONS AND FUTURE PERSPECTIVES}

All of the classes of compounds described here show very interesting properties; future developments could give promising results for the diagnosis and therapy of many diseases, especially for cancer.

Peptide-modified nanovectors can be used to selectively carry a drug to target cells using an imaging probe co-incorporated into the nanovector to guide or monitor therapy. These target-selective theranostic agents represent a new frontier in cancer therapy. They are emerging as the next generation of multifunctional nanomedicine for improving the outcome of a therapy. Compared to conventional small molecule, nanotherapeutic systems have several potential advantages: they can remain in circulation for an extended period of time when injected intravenously and present a high payload capacity, reduced toxicity to healthy tissue, and improved antitumor efficacy. Theranostic agents based on nanovectors and decorated with targeted peptides are classified according their composition and their shape and size: liposomes, naposomes, micelles, polymeric micelles and micelles built around a solid core. Until now, only a few examples for each class of peptide-targeted theranostics have been developed, most of them targeting the integrin receptors; for these very promising compounds, effort should be put into the search for other peptide sequences to decorate nanovector theranostics. Nevertheless, theranostic formulations present several interesting advantages, although their clinical applications could require a fundamental reengineering of the selling and marketing processes to ensure the successful diffusion of the theranostics prior to or in parallel with therapy.

\section{ACKNOWLEDGEMENTS}

The authors would like to thank the Italian Minister for Research (MIUR) for financial support under the PRIN 2009WCNS5C and FIRB RBRN07BMCT funding projects. The authors are indebted to Mr Luca De Luca for his informatics assistance in the graphical elaborations. 
1 Byrne, J. D., Betancourt, T. \& Brannon-Pppas, L. Active targeting schemes for nanoparticle systems in cancer therapeutics. Adv. Drug Delivery Rev. 60, 16151626 (2008).

2 Janib, S. M., Moses, A. S. \& MacKay, J. A. Imaging and drug delivery using theranostic nanoparticles. Adv. Drug. Delivery Rev. 62, 1052-1063 (2010).

3 Smith-Jones, P. M., Bischof, C., Leimer, M., Gludovacz, D., Angelberger, P., Pangerl, T. Peck-Radosavljevic, M., Hamilton, G., Kaserer, K., Kofler, A., Schlagbauer-Wadl, H., Traub, T. \& Virgolini, I. DOTA-lanreotide: a novel somatostatin analog for tumor diagnosis and therapy. Endocrinology 140, 5136-5148 (1999).

4 Aloj, L., Panico, M., Caracò, C., Del Vecchio, S., Arra, C., Affuso, A., Tesauro, D., De Luca, S., Pedone, C., Morelli, G. \& Salvatore, M. In vitro and in vivo evaluation of $111 \mathrm{In}$-DTPAGlu-G-CCK8 for cholecystokinin-B receptor imaging. Journal of Nucl. Med. 45, 485-494 (2004)

5 Rogers, B. E., Bigott, H. M., McCarthy, D. W., Della Manna, D., Kim, J., Sharp, T. L. \& Welch, M. J. MicroPET imaging of a gastrin-releasing peptide receptor-positive tumor in a mouse model of human prostate cancer using a 64Cu-labeled bombesin analogue. Bioconjug. Chem. 14, 756-763 (2003).

6 Farokhzad, O. C., Karp, J. M. \& Langer, R. Nanoparticle aptamer bioconjugates for cancer targeting. Expert Opinion Drug Delivery 3, 311-324 (2006).

7 Torchilin, V. Antibody-modified liposomes for cancer chemotherapy. Expert Opinion on Drug Delivery 5, 1003-1025 (2008).

8 Sofou, S. \& Sgouros, G. Antibody-targeted liposomes in cancer therapy and imaging. Expert Opinion on Drug Delivery 5, 189-204 (2008).

9 Wu, H. \& Chang, D. -K. Peptide-mediated liposomal drug delivery system targeting tumor blood vessels in anticancer therapy. Journal of Oncology 2010, 723798 (2010).

10 James, J. S. \& Dubs, G. FDA approves new kind of lymphoma treatment. AIDS Treat News 284, 2-3 (1997)

11 Albanell, J. \& Baselga, J. Trastuzumab: a humanized anti-HER2 monoclonal antibody, for the treatment of breast cancer. Drugs Today 35, 931-946 (1999).

12 Ferrara, N. VEGF as a therapeutic target in cancer. Oncology 69, 11-16 (2005).

13 Van Cutsem, E., Köhne, C. H., Hitre, E., Zaluski, J., Chang Chien, C. -R., Makhson, A. D'Haens, G., Pintér, T., Lim, R., Bodoky, G., Roh, J. K., Folprecht, G., Ruff, P., Stroh, C., Tejpar, S., Schlichting, M., Nippgen, J. \& Rougier, P. Cetuximab and chemotherapy as initial treatment for metastatic colorectal cancer. N. Engl. J. Med. 360, 1408-1417 (2009).

14 Murdaca, G., Colombo, B. M. \& Puppo, F. Adalimumab for the treatment of immunemediated diseases: an update on old and recent indications. Drugs of Today 47, 277-288 (2011).

15 Wilson, D. S. \& Szostak, J. W. In vitro selection of functional nucleic acids. Ann. Rev. Biochem. 68, 611-647 (1999).

16 Bates, P. J., Kahlon, J. B., Thomas, S. D., Trent, J. O. \& Miller, D. M. Antiproliferative activity of G-rich oligonucleotides correlates with protein binding. J. Biol. Chem. 274 26369-26377 (1999).

17 Bates, P. J., Laber, D. A., Miller, D. M., Thomas, S. D. \& Trent, J. O. Discovery and development of the G-rich oligonucleotide AS1411 as a novel treatment for cancer. Exp. Mol. Pathol. 86, 151-164 (2009).

18 Mongelard, F. \& Bouvet, P. AS-1411, a guanosine-rich oligonucleotide aptamer targeting nucleolin for the potential treatment of cancer, including acute myeloid leukemia. Curr. Opin. Mol. Ther. 12, 107-114 (2010).

19 Bouchard, P. R., Hutabarat, R. M. \& Thompson, K. M. Discovery and development of therapeutic aptamers. Annu Rev Pharmacol. Toxicol. 50, 237-257 (2010).

20 Beekman, K. W., Colevas, A. D., Cooney, K., Dipaola, R., Dunn, R. L., Gross, M., Keller, E. T., Pienta, K. J., Ryan, C. J., Smith, D. \& Hussain, M. Phase II evaluations of cilengitide in asymptomatic patients with androgen-independent prostate cancer: scientific rationale and study design. Clin. Genitourin. Cancer 4, 299-302 (2006).

21 Wang, A. Z., Gu, F., Zhang, L., Chan, J. M., Radovic-Moreno, A., Shaikh, M. R. \& Farokhzad, O. C. Biofunctionalized targeted nanoparticles for therapeutic applications. Expert Opin. Biol. Ther. 8, 1063-1070 (2008).

22 Ladner, R. C. Sato, A. K., Gorzelany, J. \& de Souza, M. Phage display-derived peptides as therapeutic alternatives to antibodies. Drug Discovery Today 9, 525-529 (2004).

23 Jarzyna, P. A., Gianella, A., Skajaa, T., Knudsen, G., Deddens, L. H., Cormode, D. P., Fayad, Z. A. \& Mulder, W. J. M. Multifunctional imaging nanoprobes. Wiley Interdiscip. Rev. Nanomed. Nanobiotechnol. 2, 138-150 (2010).

24 Mulder, W. J., Castermans, K., van Beijnum, J. R., Oude Egbrink, M. G., Chin, P. T., Fayad, Z. A., Löwik, C. W., Kaijzel, E. L., Que, I., Storm, G., Strijkers, G. J., Griffioen, A. W. \& Nicolay, K. Molecular imagingof tumor angiogenesis using alphavbeta3-integrin targeted multimodal quantum dots. Angiogenesis 12, 17-24 (2009).

25 Willmann, J. K., van Bruggen, N., Dinkelborg, L. M. \& Gambhir, S. S. Molecular imaging in drug development. Nat. Rev. Drug Discovery 7, 591-607 (2008).

26 Thakare, V. S., Das, M., Jain, A. K., Patil, S. \& Jain, S. Carbon nanotubes in cancer theragnosis. Nanomedicine 5, 1277-1301 (2010).

27 Liu, Y., Miyoshi, H. \& Nakamura, M. Nanomedicine for drug delivery and imaging: a promising avenue for cancer therapy and diagnosis using targeted functional nanoparticles. Int. J. Cancer 120, 2527-2537 (2007).

28 Williams, D. F. On the nature of biomaterials. Biomaterials 30, 5897-5909 (2009).

29 Kim, K., Kim, J. H., Park, H., Kim, Y. S., Park, K., Nam, H., Lee, S., Park, J. H., Park, R. W., Kim, I. S., Choi, K., Kim, S. Y., Park, K. \& Kwon, I. C. Tumor-homing multifunctional nanoparticles for cancer theragnosis: simultaneous diagnosis, drug delivery, and therapeutic monitoring. J. Control. Release 146, 219-27 (2010).

30 Yang, X., Hong, H., Grailer, J. J., Rowland, I. J., Javadi, A., Hurley, S. A., Xiao, Y., Yang, Y., Zhang, Y., Nickles, R. J., Cai, W., Steeber, D. A. \& Gong, S. cRGD-functionalized, DOX-conjugated, and ${ }^{64} \mathrm{Cu}$-labeled superparamagnetic iron oxide nanoparticles for targeted anticancer drug delivery and PET/MR imaging. Biomaterials 32, 4151-4160 (2011).

31 Nasongkla, N., Shuai, X. T., Ai, H., Ai, H., Weinberg, B. D., Pink, J., Boothman, D. A. \& Gao, J. cRGD functionalized polymer micelles for targeted doxorubicin delivery. Angew. Chem. Int. Ed. Engl. 43, 6323-6327 (2004).

32 Singh, R. \& Lillard, J. W. Nanoparticles-based targeted drug delivery. Exper. Mol. Pathol. 86, 215-223 (2009).

33 Yu, M. K., Park, J. \& Jon, S. Targeting strategies for multifunctional nanoparticles in cancer imaging and therapy. Theranostic 2, 3-44 (2012).

34 Park, K., Lee, S., Kang, E., Kim, K., Choi, K. \& Kwon, I. C. New generation of multifunctional nanoparticles for cancer imaging and therapy. Adv. Funct. Mater. 19, 1553-1566 (2009).

35 Petros, R. A. \& DeSimone, J. M. Strategies in the design of nanoparticles for therapeutic applications. Nat. Rev. Drug Discovery 9, 615-627 (2010).

36 Greish, K. Enhanced permeability and retention (EPR) effect for anticancer nanomedicine drug targeting. Cancer Nanotechnology Methods in Molecular Biology. (eds. (Stephen R. Grobmyer, B. M. M.) 624, 25-37 (Springer, Univ Florida, 2010).

37 Maeda, H., Wu, J., Sawa, T. \& Hori, K. Tumor vascular permeability and the EPR effect in macromolecular therapeutics: a review. J. Control. Release 65, 271-284 (2000).

38 Matsumura, Y. \& Maeda, H. A new concept for macromolecular therapies in cancer chemotherapy: mechanisms of tumor tropic accumulation of proteins and the antitumor agents smancs. Cancer Res. 6, 6397-6392 (1986).

39 Danhier, F., Feron, O. \& Preat, V. To exploit the tumor microenvironment: passive and active tumor targeting of nanocarriers for anti-cancer drug delivery. J. Control. Release 148, 135-146 (2010)

40 Lasic, D. D. \& Papahadjopoulos, D. Medical Applications of Liposomes (Elsevier Science, Amsterdam, 1998).

41 Hortobagyi, G. N. Anthracyclines in the treatment of cancer: an overview. Drugs 54, 1-7 (1997).

42 Gabizon, A. \& Martin, F. Polyethylene glycol-coated (pegylated) liposomal Doxorubicin: rationale for use in solid tumors. Drugs 54, 15-21 (1997).

43 Gabizon, A. Pharmacokinetics of PEGylated liposomal Doxorubicin. Clin. Pharmacokinet. 42, 419-436 (2003).

44 Abraham, S. A., Waterhouse, D. N., Lawrence, D., Cullis, P. R., Madden, T. D. \& Bally, M. B. The liposomal formulation of doxorubicin. Methods Enzymol. 391, 71-97 (2005).

45 Murphy, E. A., Majeti, B. K., Barnes, L. A., Makale, M., Weis, S. M., Lutu-Fuga, K., Wrasidlo, W. \& Cheresh, D. A. Nanoparticle-mediated drug delivery to tumor vasculature suppresses metastasis. PNAS 105, 9343-9348 (2008).

46 Gasparini, G., Brooks, P. C., Biganzoli, E., Vermeulen, P. B., Bonoldi, E., Dirix, L. Y., Ranieri, G., Miceli, R. \& Cheresh, D. A. Vascular integrin $\alpha \mathrm{v} \beta 3$ : a new prognostic indicator in breast cancer. Clin. Cancer Res. 4, 2625-2634 (1998).

$47 \mathrm{He}$, X., Na, M. H., Kim, J. S., Lee, G. -Y., Park, J. Y., Hoffman, A. S., Nam, J. O., Han, S. -E., Sim, G. Y., Oh, Y. -K., Kim, I. -S. \& Lee, B. -H. A novel peptide probe for imaging and targeted delivery of liposomal doxorubicin to lung tumor. Mol. Pharmaceutics 8 , 430-438 (2011).

48 Accardo, A., Morisco, A., Tesauro, D., Pedone, C. \& Morelli, G. Naposomes: a new class of peptide derivatized target selective multimodal nanoparticles for imaging and therapeutic applications. Therapeutic Delivery 2, 235-257 (2011).

49 Vaccaro, M., Mangiapia, G., Radulescu, A., Schillén, K., D’Errico, G., Morelli, G. \& Paduano, L. Colloidal particles composed of amphiphilic molecules binding gadolinium complexes and peptides as tumor-specific contrast agents in MRI: physico-chemical characterization. Soft Matter 5, 2504-2512 (2009).

50 Reubi, J. C., Schaer, J. C. \& Waser, B. Cholecystokinin (CCK)-A and CCK-B/gastrin receptors in human tumors. Cancer Res. 57, 1377-1386 (1997)

51 Dufresne, M., Seva, C. \& Fourmy, D. Cholecystokinin and gastrin receptors. Physiol. Rev. 86, 805-847 (2006).

52 Markwalder, R. \& Reubi, J. C. Gastrin-releasing peptide receptors in the human prostate: relation to neoplastic transformation. Cancer Res. 59, 1152-1159 (1999).

53 Gugger, M. \& Reubi, J. C. Gastrin-releasing peptide receptors in non-neoplastic and neoplastic tuman breast. Am. J. Pathol. 155, 2067-2076 (1999).

54 Fleischmann, A., Waser, B. \& Reubi, J. C. Overexpression of gastrin-releasing peptide receptors in tumor-associated blood vessels of human ovarian neoplasms. Cell. Oncol. 29, 421-433 (2007)

55 Reubi, J. C., Waser, B., Schaer, J. C. \& Laissue, J. A. Somatostatin receptor sst1-sst5 expression in normal and neoplastic human tissues using receptor autoradiography with subtype-selective ligands. Eur. J. Nucl. Med. 28, 836-846 (2001).

56 Bell, G. \& Reisine, T. Molecular biology of somatostatin receptors. Trends Neurosci. 16, 34-38 (1993)

57 Reubi, J. C., Horisberger, U. \& Laissue, J. High density of somatostatin receptors in veins surrounding human cancer tissue: role in tumor host interaction? Int. J. Cancer 56, 681-688 (1994)

58 Accardo, A., Tesauro, D., Aloj, L., Tarallo, L., Arra, C., Mangiapia, G., Vaccaro, M., Pedone, C., Paduano, L. \& Morelli, G. Peptide containing aggregates as selective nanocarriers for therapeutics. ChemMedChem 3, 594-602 (2008).

59 Morisco, A., Accardo, A., Tesauro, D., Palumbo, R., Benedetti, E. \& Morelli, G. Peptidelabeled supramolecular aggregates as selective doxorubicin carriers for delivery to tumor cells. Biopolymers (Peptide Sciences) 96, 88-96 (2011).

60 Accardo, A., Salzano, G., Morisco, A., Aurilio, M., Parisi, A., Maione, F., Cicala, C., Tesauro, D., Aloj, L., De Rosa, G. \& Morelli, G. Peptide modified liposomes for selective targeting of bombesin receptors overexpressed by cancer cells: a potential theranostic agent. Int. J. Nanomed. 7, 2007-2017 (2012).

61 Jones, M. \& Leroux, J. Polymeric micelles-a new generation of colloidal drug carriers. Eur. J. Pharm. Biopharm. 48, 101-111 (1999). 
62 Sutton, D., Nasongkla, N., Blanco, E. \& Gao, J. Functionalized micellar systems for cancer targeted drug delivery. Pharm. Res. 24, 1029-1046 (2007).

63 Shuai, X., Ai, H., Nasongkla, N., Kim, S. \& Gao, J. Micellar carriers based on block copolymers of poly(epsilon-caprolactone) and poly(ethylene glycol) for doxorubicin delivery. J. Control. Release 98, 415-426 (2004).

64 Rowe, M. D., Thamm, D. H., Kraft, S. L. \& Boyes, S. G. Polymer-modified gadolinium metal-organic framework nanoparticles used as multifunctional nanomedicines for the targeted imaging and treatment of cancer. Biomacromolecules 10, 983-993 (2009).

65 Xiao, Y., Hong, H., Javadi, A., Engle, J. W., Xu, W., Yang, Y., Zhang, Y., Barnhart, T. E., Cai, W. \& Gong, S. Multifunctional unimolecular micelles for cancer-targeted drug delivery and positron emission tomography imaging. Biomaterials 33, 3071-3082 (2012).

66 Hong, H. -Y., Lee, H. Y., Kwak, W., Yoo, J., Na, M. -H., So, I. S., Kwon, T. -H., Park, H. -S., Huh, S., Oh, G. T., Kwon, I. -C., Kim, I. -S. \& Lee, B. -H. Phage display selection of peptides that home to atherosclerotic plaques: IL-4 receptor as a candidate target in atherosclerosis. J. Cell. Mol. Med. 12, 2003-2014 (2008).

67 Park, K., Hong, H. -Y., Moon, H. J., Lee, B. -H., Kim, I. -S., Kwon, I. C. \& Rhee, K. A new atherosclerotic lesion probe based on hydrophobically modified chitosan nanoparticles functionalized by the atherosclerotic plaque targeted peptides. J. Control. Release 128, 217-223 (2008)

68 Wu, X. L., Kim, J. H., Koo, H., Bae, S. M., Shin, H., Kim, M. S., Lee, B. -H., Park, R. -W., Kim, I. -S., Choi, K., Kwon, I. C., Kim, K. \& Lee, D. S. Tumor-targeting peptide conjugated $\mathrm{pH}$ responsive micelles as a potential drug carrier for cancer therapy. Bioconjugate Chem. 21, 208-213 (2010).

69 Christian, S., Pilch, J., Akerman, M. E., Porkka, K., Laakkonen, P. \& Ruoslahti, E. Nucleolin expressed at the cell surface is a marker of endothelial cells in angiogenic blood vessels. J. Cell. Biol. 163, 871-878 (2003).

70 Reddy, G. R., Bhojani, M. S., McConville, P., Moody, J., Moffat, B. A., Hall, D. E., Kim, G., Koo, Y. E., Woolliscroft, M. J., Sugai, J. V., Johnson, T. D., Philbert, M. A., Kopelman, R., Rehemtulla, A. \& Ross, B. D. Vascular targeted nanoparticles for imaging and treatment of brain tumors. Clin. Cancer Res. 12, 6677-6686 (2006).

71 Nasongkla, N., Bey, E., Ren, J., Ai, H., Khemtong, C., Guthi, J. S., Chin, S. -F., Sherry, A. D., Boothman, D. A. \& Gao, J. Multifunctional polymeric micelles as cancertargeted, MRI-ultrasensitive drug delivery systems. Nano Lett. 6, 2427-2430 (2006),

72 Blanco, E., Kessinger, C. W., Sumer, B. D. \& Gao, J. Multifunctional micellar nanomedicine for cancer therapy. Experimental Biology and Medicine 234 123-131 (2009).

73 Guthi, J. S., Yang, S. -G., Huang, G., Li, S., Khemtong, C. Kessinger, C. W., Peyton, M., Minna, J. D., Brown, K. C. \& Gao, J. MRI-visible micellar nanomedicine for targeted drug delivery tolung cancer cells. Mol. Pharmaceutics 7, 32-40 (2010).

74 Gianella, A., Jarzyna, P. A., Mani, V., Ramachandran, S., Calcagno, C., Tang, J., Kann, B., Dijk, W. J. R., Thijssen, V. L., Griffioen, A. W., Storm, G., Fayad, Z. A. \& Mulder, W. J. M. Multifunctional nanoemulsion platform for imaging guided therapy evaluated in experimental cancer. Nano Acs 5, 4422-4433 (2011).
75 Simberg, D., Duza, T., Park, J. H., Essler, M., Pilch, J., Zhang, L., Derfus, A. M. Yang, M., Hoffman, R. M., Bhatia, S., Sailor, M. J. \& Ruoslahti, E. Biomimetic amplification of nanoparticle homing to tumors. PNAS 104, 932-936 (2007).

76 Agemy, L., Sugahara, K. N., Kotamraju, V. R., Gujraty, K., Girard, O. M., Kono, Y., Mattrey, R. F., Park, J. -H., Sailor, M. J., Jimenez, A. I., Cativiela, C., Zanuy, D., Sayago F. J., Aleman, C., Nussinov, R. \& Ruoslahti, E. Nanoparticle-induced vascular blockade in human prostate cancer. Blood 116, $2847-2856$ (2010).

77 Agemy, L., Friedmann-Morvinski, D., Kotamraju, V. R., Roth, L., Sugahara, K. N., Girard, O. M., Mattrey, R. F., Verma, I. M. \& Ruoslahti, E. Targeted nanoparticle enhanced proapoptotic peptide as potential therapy for glioblastoma. PNAS 108, 17450-55 (2011).

78 Wang, Y. \& Leaf, H. Multifunctional theranostic nanoparticles for brain tumors. Molecular Therapy 20, 10-11 (2012).

79 Mok, H., Veiseh, O., Fang, C., Kievit, F. M., Wang, F. Y., Park, J. O. \& Zhang, M. pH Sensitive siRNA nanovector for targeted gene silencing and cytotoxic effect in cancer cells. Mol. Pharm. 7, 1930-9 (2010).

80 Lyons, S. A., O'Neal, J. \& Sontheimer, H. Chlorotoxin, a scorpion-derived peptide, specifically binds to gliomas and tumors of neuroectodermal origin. Glia 39, 162-173 (2002).

81 Kumar, M., Yigit, M., Dai, G., Moore, A. \& Medarova, Z. Image-guided breast tumor therapy using a small interfering RNA nanodrug. Cancer Res. 70, 7553-7561 (2010).

82 von Maltzahn, G., Park, J. H., Lin, K. Y., Singh, N., Schwöppe, C., Mesters, R., Berdel W. E., Ruoslahti, E., Sailor, M. J. \& Bhatia, S. N. Nanoparticles that communicate in vivo to amplify tumor targeting. Nat. Mater. 10, 545-552 (2011).

83 Park, J. H., von Maltzahn, G., Zhang, L., Schwartz, M. P., Ruoslahtim, E., Bhatia, S. N. \& Sailor, M. J. Magnetic iron oxide nanoworms for tumor targeting and imaging. Adv. Mater. 20, 1630-5 (2008).

84 Alivisatos, A. P. Semiconductor clusters, nanocrystals, and quantum dots. Science 271, 933-937 (1996).

85 Bruchez, M., Moronne, M., Gin, P., Weiss, S. \& Alivisatos, A. P. Semiconductor nanocrystals as fluorescent biological labels. Science 281, 2013-2016 (1998).

$86 \mathrm{Hu}$, R., Yong, K. -T., Roy, I., Ding, H., Law, W. -C., Cai, H., Zhang, X., Vathy, L. A., Bergey, E. J. \& Prasad, P. N. Functionalized near-infrared quantum dots for in vivo tumor vasculature imaging. Nanotechnology 21, 145105 (2010).

87 Cheng, S. -H., Lee, C. -H., Chen, M. -C., Souris, J. S., Tseng, F. -G., Yang, C. -S. Mou, C. -Y., Chen, C. -T. \& Lo, L. -W. Tri-functionalization of mesoporous silica nanoparticles for comprehensive cancer theranostics-the trio of imaging, targeting and therapy. J. Mater. Chem. 20, 6149-6157 (2010).

88 Ashley, C. E., Carnes, E. C., Phillips, G. K., Padilla, D., Durfee, P. N., Brown, P. A. Hanna, T. N., Liu, J., Phillips, B., Carter, M. B., Carroll, N. J., Jiang, X., Dunphy, D. R. Willman, C. L., Petsev, D. N., Evans, D. G., Parikh, A. N., Chackerian, B., Wharton, W., Peabody, D. S. \& Brinker, C. J. The targeted delivery of multicomponent cargos to cancer cells by nanoporous particle-supported lipid bilayers. Nature Materials 10, 389-397 (2011).

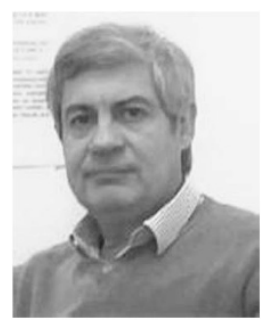

Professor Giancarlo Morelli earned a PhD in Chemistry from the University of Napoli in 1980 and did a postdoctoral stay at ETH Zurich from 1981. Presently he is full professor of General and Inorganic Chemistry at the Faculty of Pharmacy of University of Naples 'Federico II'. He is Director of the Research Center on Bioactive Peptides-CIRPeB. Giancarlo Morelli's research interest lies in peptide chemistry and in the study of the interaction between bioactive peptides and metal ions. The relationship between structure and activity of several peptide systems has been the object of his investigations, carried out with a variety of experimental techniques. The research goal is the development of new peptide conjugates as diagnostics, for nuclear medicine and MRI techniques, and therapeutics. More recently, scientific interest has been addressed to the development of peptide-based target-selective delivery systems for diagnostics and drugs. G Morelli is the author of more than one hundred papers and of several patents. Giancarlo Morelli coordinates multicenter research projects at national and international levels. He is a member of the Italian Society of Chemistry, and of the Italian Network on Metals in Biological Systems.

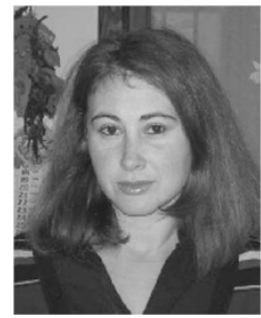

Dr Accardo Antonella obtained her master degree in Chemistry at the University of Naples 'Federico II' in 2001. She completed her $\mathrm{PhD}$ studies in Biotechnology Sciences in 2004 under the advisorship of Professor E Benedetti, defending a thesis on 'Peptide conjugates as diagnostic tools'. During PhD studies, she spent 6 months as scientific visitor in 'Laboratoire de Chimie de coordination' (LCC) of the CNRS in Toulouse (France) and 6 years as postdoctoral researcher in the Department of Biological Sciences in Naples. In December 2010, she was appointed Assistant Professor in Chemistry by the Pharmacy Faculty of the University of Naples 'Federico II'. In the past 10 years, her research interests have focused on the synthesis of peptide derivatives and formulation of new supramolecular aggregates, such as micelles and liposomes as target-selective contrast agents in MRI and as drug delivery systems (DDS) for cancer diagnosis and therapy. These topics have aroused the interest of small- and medium-sized Italian enterprises filing one patent application. She is the author of more than 30 scientific publications in peer-reviewed journals and a wide number of proceedings at international congresses. 


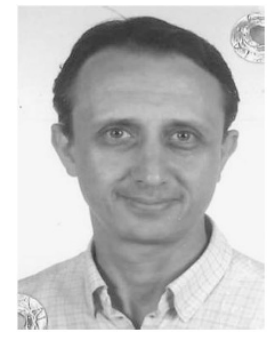

Dr Diego Tesauro was born in Naples (Italy) in 1965 and obtained his master degree in Chemistry at the University of Napoli Federico II with the maximum points in 1991. He completed his PhD studies in Chemistry in 1994, defending a thesis on reactivity of d $\mathrm{d}^{8}$ ions coordination complexes. He spent 6 month as Scientific visitor in the Roche Company in Basel (Switzerland) and 3 years as postdoctoral researcher in the Department of Chemistry in Naples. In 1998 he received a grant in Biocristallografic Centre CNR-in the field of synthesis of bioinorganic compounds. In 1999 he was appointed Assistant Professor in Chemistry by the Science Faculty of the University of Napoli 'Federico II'. His current research lies in peptide conjugates chemistry. The synthesis and characterization of tools based on peptides as contrast agents for cancer diagnoses and therapies have been the object of his investigations, carried out with a wide variety of experimental techniques. Furthermore, his research activity was directed to the formulation of new supramolecular aggregates like specific contrast agents in MRI and tools to deliver drugs in cancer cells. These topics have aroused the interest of enterprises in filing four patent applications. He is the author of 50 scientific publications in peer-reviewed journals and a wide number of proceedings at international congresses. 